\title{
AC 2009-1864: REQUIRING A MASTER'S DEGREE OR ITS EQUIVALENT AS A MODEL LAW PREREQUISITE FOR LICENSURE AFTER 2020
}

\section{Craig Musselman, CMA Engineers}

Craig N. Musselman, P.E., Dist.M.ASCE is the founder and president of CMA Engineers, a civil and environmental consulting engineering firm based in Portsmouth, $\mathrm{NH}$. He is a former member of the NH PE Board, and has served as a member of committees and task forces of ASCE, NSPE and NCEES dealing with engineering education requirements for licensure. He is also a member of the Board of Directors of ABET. 


\begin{abstract}
In 2006, the National Council of Examiners of Engineers and Surveyors (NCEES) modified the Model Law for the licensure of Professional Engineers to require an increase in the educational qualifications for licensure in the future. As of 2020, the Model Law requires a baccalaureate degree from a program accredited by the Engineering Accreditation Commission (EAC) of ABET plus a master's degree from an institution which has EAC ABET accredited programs, or the equivalent of a master's degree. This paper presents the rationale for this change and describes the current status of on-going deliberations regarding implementation details.
\end{abstract}

\title{
BACKGROUND-RAISING THE BAR IN THE FUTURE
}

The most frequently cited premise that precipitated the adoption of additional engineering education requirements by NCEES is the assertion that the body of knowledge related to the licensed practice of engineering has dramatically expanded in recent decades and will continue to do so. Concurrently, the number of credit hours required for graduation has decreased due primarily to political and economic pressures in virtually all states to provide baccalaureate programs with fewer hours of coursework. Thus, the body of knowledge required to enter the practice of engineering in the future does not fit within the curricula currently provided by undergraduate engineering programs.

This is generally reflected in the following statement, which is provided in the report entitled "Educating the Engineer of 2020,"(1) prepared by the National Academy of Engineering ${ }^{1}$ (NAE) Report in 2005:

\section{"It is evident that the exploding body of science and engineering knowledge cannot be accommodated within the context of the traditional four year baccalaureate degree."}

The concept of an advanced degree as the first "professional degree" for engineering licensure has been promoted within the engineering profession since licensure first became an initiative in each of the states. Indeed, the first statement recommending consideration of the development of professional schools for engineering was adopted by the National Society of Professional Engineers (NSPE) in October 1938. With the advancement of technology and the increased depth of basic mathematics and science needed for an engineering career, the rationale was presented that a longer period of preparation was needed. Hence, this issue is not something new to the engineering profession; it has been deliberated for 70 years. Numerous academic studies, dating back to as early as 1918, have suggested the need for engineering education beyond the baccalaureate level.

Based on this current information and the history, many in the engineering profession conclude that additional engineering education beyond the four-year ABET/EAC degree will reasonably be required in order to meet the formal academic preparation necessary for entry into the practice of engineering at the professional level (licensure) in the $21^{\text {st }}$ century. This is one component of the obligation of professional engineers to attain competence in their discipline of practice-and 
to subsequently maintain and grow their knowledge to keep pace with advances in mathematics, science, technology, and engineering.

Many in the engineering profession believe that this is about the very survival of engineering as a learned profession. The professional engineer is in jeopardy of being categorized as a technologist or technician-led and managed by individuals external to the engineering profession. Several decades ago, almost all state DOT directors were P.E.'s. Now, only about one-third are P.E.'s. This is a continuing trend, and it is a trend that is contrary to the interest of the public health, safety, and welfare - as public policy decisions with technical components are made more and more by non-engineers. Requiring additional engineering education as a prerequisite for licensure, with the added technical and professional practice breadth and depth which such reform would allow, is a step in the direction of changing public perceptions which have led to this alarming trend.

\section{REQUIREMENTS AS A PREREQUISITE FOR LICENSURE IN THE FUTURE}

NCEES has been studying this issue for the last eight years. The "Engineering Licensure Qualifications Task Force (ELQTF) Report" (2) was published in 2003. This report was prepared in collaboration among NCEES and 11 engineering societies. ELQTF recommended, unanimously, that additional education be considered as part of the requirements for licensure in the future. The report was accepted by NCEES in 2003 and passed on to the NCEES Licensure Qualifications Oversight Group (LQOG). LQOG performed additional research and considered the conclusions and recommendations of ELQTF, solely from an NCEES and regulatory perspective. LQOG agreed with the ELQTF conclusion and recommended that NCEES consider adding language to the Model Law (3) requiring additional engineering education beyond the BS level as a prerequisite for licensure in the future. In 2005, the concept of the bachelor's plus was approved by NCEES at the Annual Meeting, and subsequently the NCEES Committee on Uniform Procedures and Legislative Guidelines (UP\&LG) began drafting language to modify the Model Law and Model Rules (4) to include the bachelor's plus concept in the future.

In 2006, NCEES adopted a change to the Model Law requiring professional engineers to earn, after the year 2015, a bachelor's degree plus either a master's degree in engineering or 30 additional credits as a prerequisite for licensure as a professional engineer. The Model Law is a guidance document for state licensing boards and legislatures to follow. Each state must individually determine if and when it will adopt this Model Law change.

The additional engineering education could be completed any time between graduation at the bachelor's level and the granting of the P.E. license. Coursework would be in engineering, mathematics, science, and professional practice topic areas. The required content of "acceptable coursework" will be established in Model Rules.

The Model Law was modified in 2008 to initiate the additional engineering education requirements in 2020 rather than 2015 to provide additional time for implementation. This is the beginning date of a likely process over many years for individual jurisdictions to consider increasing education requirements.

HOW WILL THIS WORK? WHAT ARE THE DETAILS? 
The Model Law as of 2020 requires an ABET EAC accredited BS degree, or equivalent, plus a master's degree in engineering from an institution which otherwise provides ABET EAC accredited programs, or its equivalent.

The Model Law language provides a defined equivalent of a master's degree in engineering as 30 credits beyond the BS degree of "acceptable" upper level undergraduate or graduate level coursework in "technical or professional practice" topic areas from "approved providers". "Acceptable" coursework is defined as being equivalent in intellectual rigor and learning assessment to engineering coursework provided by ABET EAC accredited programs. "Technical or professional practice" topic areas are defined as engineering, math and science in the technical realm, and professional practice topics such as business, communications, contract law, management, ethics, public policy, and quality control. Coursework could be all engineering, or could be part engineering and the rest math, science and professional practice topics. The minimum engineering component is currently being deliberated by NCEES. An "approved provider" can be any institution which offers ABET EAC accredited engineering programs, or, alternatively, an institution, company or engineering society which obtains approval as providing acceptable coursework as defined. This flexible pathway (the " 30 " of the $\mathrm{B}+\mathrm{M} / 30$ ) allows an engineer intern, while working, to take acceptable coursework from multiple sources and accomplish the established educational objectives. This might allow, for example, a young engineer with the US Army Corps of Engineers to take on-line engineering courses from several different universities, several Army Corps colloquia which are approved for this purpose in the future, and a rigorous project management course from an engineering society.

NCEES is considering forming a "clearinghouse" which would provide services to individuals, PE Boards and institutions to facilitate additional engineering education in this fashion. For individuals, these services might include validating acceptable coursework from approved providers and providing a certificate to PE Boards attesting that the individual has met the Model Law educational requirements. Clearinghouse services for institutions and other entities would include the evaluation of course offerings and programs to approve providers in accordance with the Model Rules. Representatives of both NCEES and ABET are participating in discussions regarding the role and functions of this needed "clearinghouse".

NCEES will also be considering in 2009 a Model Law provision providing a pathway to licensure for individuals with an ABET EAC accredited master's degree. These provisions, if adopted, don't require a master's degree from an ABET accredited program, but rather will facilitate licensure for those with a master's degree from an ABET EAC accredited master's program, and who may not possess a BS degree from an ABET EAC program. Currently, many PE Boards are faced with difficult judgments as to whether, for instance, an individual with a Physics master's degree and an unaccredited master's degree in engineering meets the educational qualification of a BS degree from an ABET EAC accredited program. An accredited master's program negates the need for that judgment in that graduates are required to have met the baccalaureate level general and program requirements. 


\section{RATIONALE, IMPLEMENTATION ISSUES, AND POTENTIAL IMPACTS ON ENGINEERING EDUCATION IN THE US}

The rationale for increasing engineering educational requirements as a prerequisite for licensure in the future and comments concerning a variety of impacts and implementation issues are presented below.

\section{What is the Rationale for Raising the Bar in Engineering Education?}

- Raising the requirements for licensed professional engineers will improve the knowledge and skills of engineers entering licensed practice and serving society.

- The National Academy of Engineering concluded in its books "The Engineer of 2020" and "Educating the Engineer of 2020" (5) that the United States needs to raise the bar in engineering education.

- The American Society of Civil Engineers prepared the "Body of Knowledge," (6) outlining the knowledge, skills, and attitudes required to begin practice as a professional engineer in the civil engineering discipline. No one to date has provided any input to the effect that the Body of Knowledge goes too far. In fact, the second edition of the publication (BOK2) (7), which was released in 2008, adds substantially to the first edition (BOK1). Of the 30 U.S. civil engineering departments that analyzed the BOK1, none indicated that the academic portion of BOK1 (much less the expanded BOK2) could be fulfilled in undergraduate engineering programs. The formal educational portion of the body of knowledge can no longer be fulfilled at the undergraduate level.

- Baccalaureate program credit hour requirements are static or declining, and curricula are full, with little or no flexibility to reduce current course requirements. Yet many contend that new topics critically need to be added to engineering curricula. Consider the following:

- Sustainability - The concept of sustainability needs to be incorporated in the engineering thought process - in education and in practice. This isn't a buzzword. From an engineering standpoint, sustainability has multiple components: conservation of energy and other resources; minimization and management of environmental impacts; economic viability; and long term operability and maintenance capability. Not only does this concept need to be incorporated in the engineering thought process in all disciplines, the public will demand it. Yet it does not, and cannot, fit in engineering curricula because there is no room for additional topics.

- Risk Analysis and Management - We as a society are hopefully learning that technical people need to be in responsible charge of risk management in technical undertakings. The Challenger disaster occurred in no small part because nonengineers are increasingly making technical risk management decisions. NASA has since fixed this by ensuring that those in responsible charge of decisionmaking are people with engineering backgrounds, but the trend continues in other areas. As a separate risk matter, the I-35 bridge collapse in Minnesota has shown that risk management procedures critically need to be incorporated in engineering practice such that, for example, the observation of gusset plate deformation on a bridge immediately triggers consideration and actions as appropriate. Risk analysis and management is integral to everything that engineers do. We teach engineering students rudimentary probability and statistics, and apply that to predicting how many ping pong balls might be black as opposed to white (perhaps 
an understatement, but not by much), but we don't teach engineering students how to apply risk analysis and management techniques to engineering applications so that risk considerations are incorporated in the engineering thought process. We do that in engineering practice on an hour to hour basis, to varying degrees, but we don't incorporate applied risk concepts in engineering education. Risk analysis and management needs to be added to engineering curricula, but it does not, and cannot, fit because there is no room for additional topics.

- Project management, public policy, leadership and globalization are topics which are necessary building blocks for an engineering career in the future. These do not fit in engineering curricula either without increasing engineering education requirements.

- In addition to the above topics, which apply equally to all engineering disciplines, the technical knowledge required for professional practice has expanded beyond the scope of current baccalaureate curricula, at least for some disciplines, as well.

- Other countries are increasing engineering education levels. The United States has provided engineering and technological leadership to the world for the last 150 years. As pointed out by the National Academy of Engineering in its recent report "Rising Above the Gathering Storm," our global competitiveness in engineering is at risk. It concludes that engineering education needs to be reformed to respond to this risk.

- A bachelor's degree in engineering provides an individual with problem-solving skills. Advanced education (the equivalent of a professional degree), with a focus on additional technical depth and professional skills relating to the individual's area of practice, adds substantially to the body of knowledge that can be attained in today's baccalaureate programs. This advanced education, combined with suitable engineering experience, is an appropriate requirement for licensure as a professional engineer in the future. In order to best protect the public health, safety and welfare in the future, we need to focus on educating and training engineers to enable them to make reasoned technical and professional judgments in an expanding technological and global environment, not on generating technicians who are adept at engineering calculations. Such technicians are needed as members of engineering teams, but they do not function at a professional engineering level.

2. What Impact have Declining Credit Hour Requirements had on the Need to Raise the Bar in Engineering Education?

- The technical breadth and depth of undergraduate engineering curricula have declined as the technical credit hour portion of the BS engineering degree has decreased over time. Engineering students do not have time to attain technical depth and, in most cases, lack exposure to project management, leadership, ethics, communications, finance, management, and other courses important and essential for many areas of professional practice in the 21st century. The additional education helps meet current voids in academic preparation both technically and professionally, and will allow engineering education reform in the future at the undergraduate level to assure that the requisite body of knowledge is attained.

- The additional credits will compensate for the decline in university requirements for a bachelor's degree in engineering from an average of 144 credits 25 years ago to an average of about 128 credits today. 
- In 2007, of those universities reporting credit requirements to the American Society for Engineering Education (ASEE) (8), over 13\% had an engineering program or programs requiring the equivalent of 120 semester credits. This is up from 5\% of universities in 1998. The decline in the total number of credit hours required for a bachelor's degree is clearly an on-going trend in engineering education.

- ABET, upon the recommendation of ASCE, recently changed the baccalaureate-level program criteria for civil engineering evaluations (beginning with the 2008-2009 accreditation cycle) to require additional professional practice topics and an additional basic science in the civil engineering curriculum. With these changes, accredited baccalaureatelevel civil engineering programs now include more needed professional practice breadth and somewhat less technical content (less depth in the breadth) than in the past. The "M/30" component of formal education has been modeled to provide the technical depth that is not in today's baccalaureate engineering programs. Changes have already been made reflecting the recommendations of NAE, NSPE, ASCE, and NCEES that additional engineering education beyond the baccalaureate degree will be a prerequisite for professional practice in the future. Without implementing the additional engineering education requirements, many individuals will not have sufficient technical depth to enter licensed practice in the future.

- In order to deal with university-mandated declining credit requirements, some engineering programs are facing hard curriculum choices, and some are considering alternatives such as dropping either a physics or a chemistry course, both of which are fundamental to the education of an engineer. Is this the direction in which we should be headed in the education of the professional engineers of the future?

\section{Won't Requiring Additional Engineering Education Create or Exacerbate a Shortage of Engineers?}

- This change in engineering licensure requirements affects only those engineering graduates who can and want to pursue a professional license (historically 20-25\% of all engineering graduates) and maintains the current BS degree for those that only want to complete that degree and be part of the engineering community or to pursue other careers. There will continue to be an excellent job market for those with a BS education in engineering, both within the "built environment" and otherwise. This flexibility in education choices will help limit potential shortages. The BS in engineering is a starting point for people pursuing many different types of careers.

- The ratio of engineering master's degrees to engineering bachelor's degrees in the United States has been increasing significantly in recent years and is now over $50 \%$. The market is already moving in the direction of additional engineering education.

- In 2008, civil engineering enrollments in U.S. universities were at an all-time high, and many of these engineering students know that higher standards for entry into professional practice are coming. Many other learned professions have increased educational requirements beyond the bachelor's level over the last century, and not one of these professions has realized shortages of professionals due to the educational requirements. Our system of supply and demand works. It always has, for all professions, and it will in the future.

- The accounting profession raised its educational standards in recent years. Between 1990 and 2005, almost all states adopted a 150 credit hour requirement for becoming a CPA. In the last three years, the number of graduates awarded bachelor's or master's degrees in accounting in 
the United States has increased 19\%, to its all-time high since records began to be kept in 1971. Increased academic requirements have not resulted in a shortage of accounting graduates or CPAs. In fact, the numbers have substantially increased.

\section{Won't this interfere with interstate licensure by comity?}

- The NCEES Engineering Education Task Force has made recommendations regarding interstate licensure by comity that will work. Comity licensure currently works better than it ever has, with more than half of states able to license a Model Law Engineer with a Council Record within a week or two. The proposed establishment of a "Model Law Engineer 2020" coupled with the continuation of the current Model Law Engineer-expedited comity programs are proposed to assure that licensure by comity continues to work. The Model Law includes provisions to assure that current and duly licensed professional engineers will be capable of being licensed in the future in states which adopt the new standards.

\section{Why can't or shouldn't ABET expand undergraduate curricula?}

- ABET does not (and cannot) dictate to colleges and universities how many credit hours will be required to obtain a bachelor's degree in engineering. ABET accredits content (in the form of self-selected objectives and outcomes), but not hours; i.e., there are no prescribed classes or number of credits. Credit requirements for a degree are set by individual university administrations and state legislatures. ABET cannot change universities' credit requirements for degrees. That is not within ABET's purview. Further, it is the responsibility of the engineering profession and those who regulate the engineering profession, not ABET, to set the required body of knowledge. ABET cannot do what is beyond its scope of authority.

- Even if ABET could require universities to increase their credit requirements for a bachelor's degree, the resulting five-year or longer bachelor's programs would provide far less flexibility than $\mathrm{B}+\mathrm{M} / 30$, at substantially greater cost to students, and would significantly increase the potential for decreased enrollments. It is difficult to create for any constituency a rationale as to why this would be preferable to the proposed $\mathrm{B}+\mathrm{M} / 30$ requirements.

\section{What are some of the implications of these changes for engineering education in the US?}

First, it should be recognized that this will likely take a long time to implement. Continuing education requirements for professional engineers were adopted first in Iowa in 1988 . Now twenty years later, about two thirds of jurisdictions have adopted similar requirements. The 2020 Model Law date is a "no earlier than" date, at which the initial jurisdictions might consider adopting these requirements.

- If all jurisdictions were to adopt the Model Law educational requirements, some of the impacts on graduate engineering education in the US would be predicted as follows:

- Graduate engineering enrollments in the US would increase by an estimated 20-30\% from current levels (assuming that the MS:BS ratio is 50\% currently, that $40 \%$ of licensed PE's currently eventually obtain an MS, and that 20-25\% of all engineering graduates become licensed professional engineers).

- Demand for distance learning/on-line upper level undergraduate and graduate engineering courses would increase significantly, as many engineers would likely choose to take courses in this fashion while working full time. 
- Demand would increase for all- coursework, or project-based, master's programs, geared toward professional practice, rather than research oriented thesis programs.

- There will be a need to provide access to upper level undergraduate and graduate level education for engineers having limited undergraduate academic performance, including for those with grade point averages which would not allow acceptance at many graduate schools. This need not be provided by elite graduate engineering programs, nor would it necessitate acceptance of substandard graduate performance, but access to graduate level coursework would need to be provided in some programs.

This Model Law change is controversial, both within the engineering profession, and within NCEES and its member PE Boards. Both the American Society of Civil Engineers and the American Academy of Environmental Engineers have concluded that the knowledge, skills and attitudes required for professional practice no longer fit within the context of current baccalaureate engineering programs. Other engineering disciplines, particularly those for whom graduate engineering education is less common for engineers practicing in the built environment, have expressed significant opposition as the Model Law requirements have been adopted. Some engineering disciplines in addition to civil and environmental engineers have begun work on defining their bodies of knowledge, while others, particularly those with limited numbers of practitioners, likely will not focus on requisite bodies of knowledge for professional practice. In that context, and with these disparate views among engineering disciplines, planning for implementing changes in engineering education requirements for the future continues.

\section{References}

(1) "Educating the Engineer of 2020, Adapting Engineering Education to the New Century", 2005, the National Academy of Engineering, NAE, Washington, D.C.

(2) "Report of the Engineering Licensure Qualifications Task Force (ELQTF), 2003, National Council of Examiners for Engineers and Surveyors (NCEES), Clemson, SC. Www.ncees.org/introduction/about_ncees/2003_elqtf_report.pdf

(3) Model Law, National Council of Examiners for Engineers and Surveyors (NCEES), August, 2008, http://www.ncees.org/introduction/about_ncees/model_law_2008.pdf

(4) Model Rules, National Council of Examiners for Engineers and Surveyors (NCEES), August, 2008, http://www.ncees.org/introduction/about_ncees/model_rules_2008.pdf

(5) "The Engineer of 2020, Visions of Engineering in the New Century", 2004, the National Academy of Engineering (NAE), Washington, D.C.

(6) "Civil Engineering Body of Knowledge for the $21^{\text {st }}$ Century", 2004, American Society of Civil Engineers, Reston, VA.

(7) "Civil Engineering Body of Knowledge for the $21^{\text {st }}$ Century, $2^{\text {nd }}$ Edition", 2008, American Society of Civil Engineers, Reston, VA http://www.asce.org/professional/educ/.

(8) Engineering Education Statistics, American Society for Engineering Education (ASEE) website: www.asee.org 
0
$\stackrel{0}{0}$
$\stackrel{0}{D}$
$\vec{D}$
$\vec{D}$
$\overrightarrow{0}$
$\stackrel{+}{ \pm}$
$\overrightarrow{0}$ 